\title{
Sistem Pendukung Keputusan Pemilihan Jenis Tanaman Karet Untuk Menghasilkan Bibit Tanaman Karet Terbaik Menggunakan Metode Topsis
}

\author{
Wasenda Dewi ${ }^{1}$, Roy Fanry Siahaan ${ }^{2}$ \\ ${ }^{1,2}$ STMIK Pelita Nusantara \\ Program Studi Teknik Informatika STMIK Pelita Nusantara \\ Jl. ST. Iskandar Muda No.1 Medan, Indonesia \\ Corresponding author's e-mail: wasendadewi2@gmail.com
}

\begin{abstract}
Abstrak - Setiap inovasi diciptakan untuk memberikan manfaat positif bagi kehidupan manusia. Teknologi juga memberikan banyak kemudahan, serta sebagai cara baru dalam melakukan aktivitas manusia. Manusia juga sudah menikmati banyak manfaat yang dibawa oleh inovasi-inovasi teknologi yang telah dihasilkan dalam dekade terakhir ini. Kemajuan teknologi untuk memudahkan pekerjaan manusia dan mempercepat kegiatan yang dilakukan pada saat bekerja. Penerapan Teknologi Informasi telah banyak digunakan oleh para usahawan. Salah satu contoh penerapan teknologi informasi adalah di dunia industri tanaman karet. Teknologi dapat digunakan dalam memberikan sebuah sistem keputusan terbaik dengan berdasarkan data yang dimiliki. Sistem yang berjalan pada perkebunan tersebut mengalami kelemahan, dan sampai saat ini belum ada sistem yang menerapkan tentang kualitas pada jenis tanaman karet. Di dalam balai penelitian sungei putih, selama ini didalam menentukan dan mengetahui jenis bibit terbaik untuk tanaman karet dilakukan dengan cara manual yaitu dengan cara memperkirakan tanpa menggunakan metode maupun sistem dalam mengambil keputusan sehingga hasil yang didapat tidak memuaskan dan bahkan mengalami kerugian dan tidak efektif dalam menentukan kualitas jenis tanaman karet. Sistem ini dibangun dengan menggunakan PHP sebagai bahasa scripting, dan MYSQL sebagai databasenya. Adapun metode di dalam sistem pendukung keputusan yang dipakai didalam penelitian ini adalah TOPSIS. Penelitian ini menggunakan data 6 kriteria, dan 4 data alternatif. Didapatkan hasil keputusan dan akurasi Karet Jelutung (Dyera costulata) dengan nilai 0.5971 Menghasilkan Kualitas Bibit Terbaik, Karet Biasa dengan nilai 0.5014 Belum Menghasilkan Kualitas Bibit Terbaik, Karet Merah atau Karet Kebo (Ficus) dengan nilai 0.483 Belum Menghasilkan Kualitas Bibit Terbaik, Tanaman Russian Dandelion (Taraxacu) dengan nilai 0.4479 Belum Menghasilkan Kualitas Bibit Terbaik, Karet Brazil (Hevea Brasilliensis) dengan nilai 0.3921 Belum menghasilkan kualitas bibit terbaik, dan Tanaman Karet Guayule dengan nilai 0.2099 Belum menghasilkan kualitas bibit terbaik.
\end{abstract}

Kata Kunci : SPK, TOPSIS, Bibit, Tanaman Karet.

Abstract- Every innovation is created to provide positive benefits for human life. Technology also provides many conveniences, as well as a new way of carrying out human activities. Humans have also enjoyed the many benefits brought by technological innovations that have been produced in the last decade. Advances in technology to facilitate human work and speed up the activities carried out at work. The application of Information Technology has been widely used by entrepreneurs. One example of the application of information technology is in the rubber plantation industry. Technology can be used to provide the best decision system based on the available data. The system that runs on these plantations has weaknesses, and until now there is no system that applies the quality of rubber plantations. In the Sungei Putih research center, so far in determining and knowing the best types of seeds for rubber plants, it is done manually, namely by estimating without using methods or systems in making decisions so that the results obtained are unsatisfactory and even suffer losses and are not effective in determining quality of rubber plant species. This system is built using PHP as the scripting language, and MYSQL as the database. The method in the decision support system used in this study is TOPSIS. This study uses 6 criteria data, and 4 alternative data. The results of the decision and accuracy of Jelutung Rubber (Dyera costulata) with a value of 0.5971 Produce the Best Quality Seeds, Ordinary Rubber with a value of 0.5014 Not yet Produce the Best Seed Quality, Red Rubber or Kebo Rubber (Ficus) with a value of 0.483 Not Produce the Best Seed Quality, Russian Dandelion Plants (Taraxacu) with a value of 0.4479 has not yet produced the best seed quality, Brazilian rubber (Hevea Brasilliensis) with a value of 0.3921 has not yet produced the best seed quality, and Guayule rubber plants with a value of 0.2099 have not produced the best seed quality.

Keywords: DSS, TOPSIS, Seedlings, Rubber Plants. 


\section{Pendahuluan}

Teknologi merupakan konsep yang sangat luas dan digunakan untuk merujuk kepada beberapa cabang ilmu pengetahuan dan penelitian [1]. Kemajuan teknologi adalah sesuatu yang tidak bisa dihindari dalam kehidupan ini, karena kemajuan teknologi akan berjalan sesuai dengan kemajuan ilmu pengetahuan. Setiap inovasi diciptakan untuk memberikan manfaat positif bagi kehidupan manusia. Teknologi juga memberikan banyak kemudahan, serta sebagai cara baru dalam melakukan aktivitas manusia. Manusia juga sudah menikmati banyak manfaat yang dibawa oleh inovasi-inovasi teknologi yang telah dihasilkan dalam dekade terakhir ini. Kemajuan teknologi untuk memudahkan pekerjaan manusia dan mempercepat kegiatan yang dilakukan pada saat bekerja [2]. Penerapan Teknologi Informasi telah banyak digunakan oleh para usahawan. Salah satu contoh penerapan teknologi informasi adalah di dunia industri tanaman karet. Teknologi dapat digunakan dalam memberikan sebuah sistem keputusan terbaik dengan berdasarkan data yang dimiliki.

Tanaman Karet (Hevea brasiliensis Muell. Arg) merupakan salah satu komoditas perkebunan yang penting baik untuk lingkup Indonesia maupun bagi internasional. Indonesia pernah menguasai produksi karet dunia dengan mengungguli produksi negara-negara lain. Tanaman karet merupakan salah satu komoditi perkebunan yang menduduki posisi cukup penting sebagai sumber devisa non migas bagi Indonesia. Tujuan dari budidaya tanaman karet alam adalah memproduksi lateks dan bekuannya. Lateks dan bekuannya merupakan bahan utama bagi industri yang memproduksi produk berbahan karet seperti ban, sepatu karet, balon, dan produk-produk karet lainnya. Agar menghasilkan suatu lateks dan bekuan yang baik maka kualitas tanaman karet harus baik pula. Kualitas tanaman karet yang baik tergantung dengan beberapa hal seperti kualitas bibit karet, lahan perkebunan, iklim, penyadapan serta proses pemanenannya [3]. Salah satu cara untuk mengetahui bibit terbaik pada tanaman karet adalah dengan melakukan sebuah penelitian tentang tanaman karet.

Balai penelitian sungei putih merupakan salah satu pusat penelitian di deli serdang yang mempunyai mandat utama melaksanakan penelitian dan pengembangan komoditas karet. Sistem yang berjalan pada perkebunan tersebut mengalami kelemahan, dan sampai saat ini belum ada sistem yang menerapkan tentang kualitas pada jenis tanaman karet. Di dalam balai penelitian sungei putih, selama ini didalam menentukan dan mengetahui jenis bibit terbaik untuk tanaman karet dilakukan dengan cara manual yaitu dengan cara memperkirakan tanpa menggunakan metode maupun sistem dalam mengambil keputusan sehingga hasil yang didapat tidak memuaskan dan bahkan mengalami kerugian dan tidak efektif dalam menentukan kualitas jenis tanaman karet Adapun cara yang direkomendasikan didalam penelitian ini adalah dengan menggunakan sistem pendukung keputusan.

Adapun metode di dalam sistem pendukung keputusan yang dipakai didalam penelitian ini adalah TOPSIS. Metode TOPSIS pertama kali diperkenalkan oleh Hwang dan Yoon. TOPSIS merupakan metode multikriteria untuk mengidentifikasi dari himpunan alternatif terbatas berdasarkan meminimalkan jarak titik ideal terjauh dan memaksimalkan jarak titik ideal terendah [4].

Penelitian ini dirasa perlu untuk dilakukan karena untuk membantu dalam menentukan jenis kualitas terbaik pada bibit tanaman karet agar mendapatkan hasil produksi dan penjualan yang baik dnegan menggunakan Sistem pendukung keputusan.

\section{Tinjauan Pustaka}

\subsection{Sistem Pendukung Keputusan}

Sistem pendukung keputusan adalah sistem informasi berbasis komputer yang interaktif, dengan cara mengolah data dengan berbagai model untuk memecahkan masalah-masalah yang tidak terstruktur sehingga dapat memberikan informasi yang bisa digunakan oleh para pengambil keputusan dalam membuat sebuah keputusan[5]. Dalam sebuah sistem pendukung keputusan, sumber daya intelektual yang dimiliki seseorang dipadukan dengan kemampuan komputer untuk membantu meningkatkan kualitas dari keputusan yang diambil. Pengambilan keputusan merupakan sebuah proses memilih sebuah tindakan diantara beberapa alternatif yang ada, sehingga tujuan yang diinginkan dapat tercapai[4].

\subsection{Metode TOPSIS}

Permasalahan pengambilan keputusan merupakan proses pencarian opsi terbaik dari seluruh alternative fisibel. Multiple criteria decision making merupakan bagian dari problem pengambilan keputusan yang relatif kompleks, yang mengikutsertakan beberapa orang pengambil keputusan, dengan sejumlah berhingga kriteria yang beragam yang harus dipertimbangkan, dan masingmasing kriteria itu memiliki nilai bobot tertentu, dengan tujuan untuk mendapatkan solusi optimal atas suatu permasalahan. Salah satu metode yang digunakan untuk menangani permasalahan ini, adalah Technique for Order Performance by Similarity to Ideal Solution (TOPSIS). [6].

TOPSIS adalah salah satu metode pengambilan keputusan multikriteria yang pertama kali diperkenalkan 
oleh Yoon dan Hwang (1981). TOPSIS menggunakan prinsip bahwa alternatif yang terpilih harus mempunyai jarak terdekat dari solusi ideal positif dan jarak terpanjang (terjauh) dari solusi ideal negatif dari sudut pandang geometris dengan menggunakan jarak Euclidean (jarak antara dua titik) untuk menentukan kedekatan relatif dari suatu alternatif dengan solusi optimal. Solusi ideal positif didefinisikan sebagai jumlah dari seluruh nilai terbaik yang dapat dicapai untuk setiap atribut, sedangkan solusi negatif-ideal terdiri dari seluruh nilai terburuk yang dicapai untuk setiap atribut.

TOPSIS mempertimbangkan keduanya, jarak terhadap solusi ideal positif dan jarak terhadap solusi ideal negatif dengan mengambil kedekatan relatif terhadap solusi ideal positif. Berdasarkan perbandingan terhadap jarak relatifnya, susunan prioritas alternatif bisa dicapai. Metode ini banyak digunakan untuk menyelesaikan pengambilan keputusan secara praktis. Hal ini disebabkan konsepnya sederhana dan mudah dipahami, komputasinya efisien, dan memiliki kemampuan mengukur kinerja relatif dari alternatifalternatif keputusan. TOPSIS banyak digunakan dengan alasan :

1. Konsepnya sederhana dan mudah dipahami.

2. Komputasinya efisien.

3. Memiliki kemampuan untuk mengukur kinerja relatif dari alternatif-alternatif keputusan dalam bentuk matematis yang sederhana[6].

\subsection{Tanaman Karet}

Karet alam (Hevea Brasiliensis) merupakan suatu komoditas yang saat ini paling banyak dikembangkan di dunia terutama oleh negara-negara produsen karet alam. Negara tersebut antara lain Malaysia, Thailand dan Indonesia. Tujuan dari budidaya tanaman karet alam adalah memproduksi lateks dan bekuannya. Lateks dan bekuannya merupakan bahan utama bagi industri yang memproduksi produk berbahan karet seperti ban, sepatu karet, balon, dan produk-produk karet lainnya. Agar menghasilkan suatu lateks dan bekuan yang baik maka kualitas tanaman karet harus baik pula. Kualitas tanaman karet yang baik tergantung dengan beberapa hal seperti kualitas bibit karet, lahan perkebunan, iklim, penyadapan serta proses pemanenannya [3].

\subsection{UML}

Unified Modeling Language (UML) adalah bahasa spesifikasi standar yang dipergunakan untuk mendokumentasikan, menspesifikasikan dan membanngun perangkat lunak. UML merupakan metodologi dalam mengembangkan sistem berorientasi objek dan juga merupakan alat untuk mendukung pengembangan sistem (uml). [7].

\subsection{PHP}

PHP (Hypertext Preprocessor) adalah bahasa script yang dapat ditanamkan atau disisipkan ke dalam HTML. PHP banyak dipakai untuk membuat program situs web dinamis, PHP dapat digunakan dengan gratis (free) dan bersifat Open Source. PHP dirilis dalam lisensi PHP license.Untuk membuat program PHP kita diharuskan untuk menginstal web server terlebih dahulu, contoh program PHP terlihat pada gambar 2.2 [8].

\section{Metode Penelitian}

Bagian ini menggambarkan bagaimana kerangka penelitian yang dilakukan agar sesuai dengan tujuan dan hasil yang diinginkan dengan waktu yang efisien. Adapun kerangka penelitian dapat dilihat pada gambar berikut:

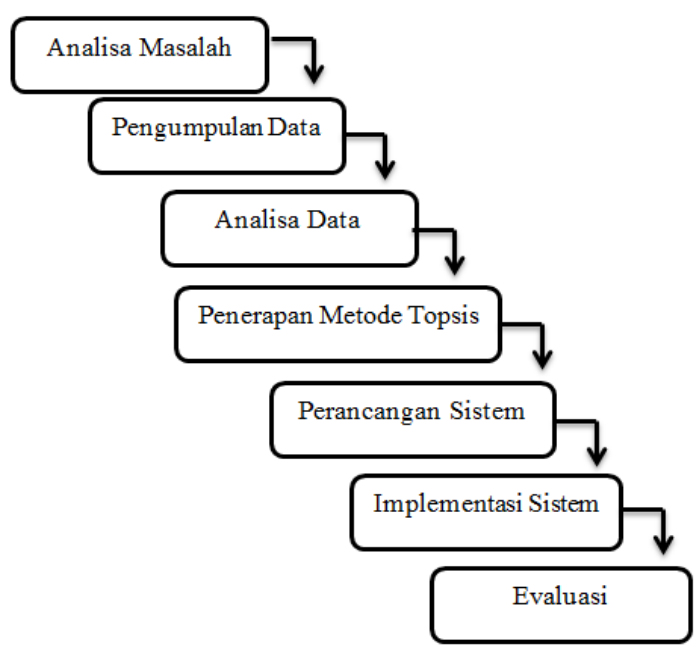

Gambar 1. Kerangka Kerja Penelitian 


\section{Hasil dan Pembahasan}

Langkah-langkah penyelesaiannya:

\subsection{Analisa Data}

Pada tahapan ini dilakukan proses analisa metode yang bertujuan untuk menyelesaikan permasalahan pada penelitian. Analisa berupa perhitungan metode yang disertai dengan data penelitian yang telah didapatkan dari tempat penelitian. Analisa juga sebagai inti pokok dari hasil keputusan pada permasalahan penelitian. Sehingga di harapkan hasil penelitian ini dapat digunakan oleh Balai Penelitian Karet Sungai Putih dalam menentukan jenis tanaman karet untuk menghasilkan bibit terbaik.

\subsection{Tempat Penelitian}

Pengumpulan data yaitu data tentang jenis-jenis tanaman karet yang ada di Balai Penelitian Karet Sungai Putih dan juga bibit tanaman karet. Pengumpulan data ini dilakukan dengan cara wawancara dan observasi di tempat penelitian Balai Penelitian Karet Sungai Putih.

\subsection{Algoritma Metode TOPSIS}

\section{Berikut ini data alternatif penelitian}

\begin{tabular}{|c|c|c|}
\hline No. & Kode & Nama Tanaman Karet \\
\hline 1. & A1001 & Karet Brazil (Hevea Brasilliensis) \\
\hline 2. & A1002 & Karet Jelutung (Dyera costulata) \\
\hline 3. & A1003 & Karet Merah atau Karet Kebo (Ficus elastica) \\
\hline 4. & A1004 & Tanaman Karet Guayule (Parthenium argentatum) \\
\hline 5. & A1005 & Tanaman Russian Dandelion (Taraxacum kok-saghyz) \\
\hline 6. & A1006 & Karet Biasa \\
\hline
\end{tabular}

Gambar 2.Data Alternatif

\section{Data Kriteria dan Bobot}

Berikut adalah data kriteria yang digunakan:

\begin{tabular}{|c|c|c|}
\hline Kode & Kriteria & Bobot Kepentingan \\
\hline C1 & Bentuk Payung & $35 \%$ \\
\hline C2 & Bentuk Daun & $15 \%$ \\
\hline C3 & Helai Daun & $25 \%$ \\
\hline C4 & Batang & $25 \%$ \\
\hline
\end{tabular}

Gambar 2. Data Kriteria

\section{Data Range masing-masing Kriteria}

Berikut adalah data range dari masing-masing kriteria: 


\begin{tabular}{|c|c|c|c|}
\hline Bentuk Payung & Terbilang & Nilai & Fuzzy \\
\hline Kurang Lebar & Kurang Baik & $30-50$ & 0.25 \\
\hline Cukup Lebar & Cukup & $51-70$ & 0.50 \\
\hline Lebar & Baik & $71-90$ & 0.75 \\
\hline Sangat Lebar & Sangat Baik & $91>=$ & 1 \\
\hline
\end{tabular}

\begin{tabular}{|c|c|c|c|}
\hline Bentuk Daun & Terbilang & Nilai & Fuzzy \\
\hline Kurang Lebar & Kurang Baik & $30-50$ & 0.25 \\
\hline Cukup Lebar & Cukup & $51-70$ & 0.50 \\
\hline Lebar & Baik & $71-90$ & 0.75 \\
\hline Sangat Lebar & Sangat Baik & $91>=$ & 1 \\
\hline
\end{tabular}

\begin{tabular}{|c|c|c|c|}
\hline Helai Daun & Terbilang & Nilai & Fuzzy \\
\hline Kurang Subur & Kurang Baik & $30-50$ & 0.25 \\
\hline Cukup Subur & Cukup & $51-70$ & 0.50 \\
\hline Subur & Baik & $71-90$ & 0.75 \\
\hline Sangat Subur & Sangat Baik & $91>=$ & 1 \\
\hline
\end{tabular}

\begin{tabular}{|c|c|c|c|}
\hline Batang & Terbilang & Nilai & Fuzzy \\
\hline Kurang Besar & Kurang Baik & $30-50$ & 0.25 \\
\hline Cukup Besar & Cukup & $51-70$ & 0.50 \\
\hline Besar & Baik & $71-90$ & 0.75 \\
\hline Sangat Besar & Sangat Baik & $91>=$ & 1 \\
\hline
\end{tabular}

Gambar 3. Data Range masing-masing kriteria

\section{Perhitungan Metode TOPSIS}

Data alternatif di konversi menjadi seperti ini:

\begin{tabular}{|c|c|c|c|c|c|}
\hline Kode & Nama & $\mathrm{C1}$ & $\mathrm{C} 2$ & $\mathrm{C} 3$ & $\mathrm{C} 4$ \\
\hline Kr001 & Karet Brazil (Hevea Brasilliensis) & 0.25 & 0.50 & 0.25 & 0.25 \\
\hline Kr002 & Karet Jelutung (Dyera costulata) & 0.50 & 0.25 & 0.75 & 0.25 \\
\hline Kr003 & Karet Merah atau Karet Kebo (Ficus elastica) & 0.75 & 0.50 & 0.50 & 0.25 \\
\hline Kr004 & Tanaman Karet Guayule (Parthenium argentatum) & 0.50 & 0.25 & 0.25 & 0.25 \\
\hline Kr005 & Tanaman Russian Dandelion(Taraxacum kok-saghyz) & 0.50 & 0.50 & 0.25 & 0.25 \\
\hline Kr006 & Karet Biasa & 0.25 & 0.25 & 0.75 & 0.50 \\
\hline
\end{tabular}

Gambar 4 Konversi Data Alternatif

Membangun Matrix keputusan ternormalisasi dari setiap kategori yang dilambangkan dengan X(i) dimana $\mathrm{i}=1,2,3$, dan 4 . Adapun rumus normalisasi matriks adalah sebagai berikut :

$R_{i j}=\frac{X}{i j}$

Maka hasilnya adalah: 


\begin{tabular}{|c|c|c|c|c|}
\hline Kode & C1 & C2 & C3 & C4 \\
\hline Kr001 & 0.2085 & 0.5164 & 0.2 & 0.3333 \\
\hline Kr002 & 0.417 & 0.2582 & 0.6 & 0.3333 \\
\hline Kr003 & 0.6255 & 0.5164 & 0.4 & 0.3333 \\
\hline Kr004 & 0.417 & 0.2582 & 0.2 & 0.3333 \\
\hline Kr005 & 0.417 & 0.5164 & 0.2 & 0.3333 \\
\hline Kr006 & 0.2085 & 0.2582 & 0.6 & 0.6667 \\
\hline
\end{tabular}

Gambar 5 Hasil Bagi masing-masing rij yang telah dinormalisasi

Dari hasil perhitungan diperoleh matriks keputusan ternormalisasi terbobot seperti pada tabel berikut

Tabel 1 Matriks Keputusan

\begin{tabular}{|c|c|c|c|}
\hline Vi1 & Vi2 & Vi3 & Vi4 \\
\hline 0.0417 & 0.1549 & 0.06 & 0.0667 \\
\hline 0.0834 & 0.0775 & 0.18 & 0.0667 \\
\hline 0.1251 & 0.1549 & 0.12 & 0.0667 \\
\hline 0.0834 & 0.0775 & 0.06 & 0.0667 \\
\hline 0.0834 & 0.1549 & 0.06 & 0.0667 \\
\hline 0.0417 & 0.0775 & 0.18 & 0.1333 \\
\hline
\end{tabular}

Menghitung kedekatan relatif dari setiap alternatif terhadap sulosi ideal positif (ci+) dengan rumus sebagai berikut :

$$
V_{i}=\frac{D_{i}}{D_{i}-+D_{i}+}
$$

Tabel 2 Kedekatan Relatif

\begin{tabular}{|c|c|c|c|}
\hline Kode & S+ & S- & C+ \\
\hline Kr001 & 0.1464 & 0.0389 & 0.5971 \\
\hline Kr002 & 0.1305 & 0.1219 & 0.5014 \\
\hline Kr003 & 0.073 & 0.1082 & 0.483 \\
\hline Kr004 & 0.1594 & 0.1028 & 0.4479 \\
\hline Kr005 & 0.1246 & 0.1011 & 0.3921 \\
\hline Kr006 & 0.14 & 0.1011 & 0.2099 \\
\hline
\end{tabular}

Meranking Alternatif Pada tabel berikut merupakan hasil proses perhitungan yang sudah terurut dari nilai yang terbesar sampai nilai yang terkecil. Hasil perangkingan setiap dapat dilihat dengan nilai ketentuan keputusan akhir dibawah ini :

\section{Ketentuan Keputusan Akhir:}

Jika Hasil >=0.5971 maka Menghasilkan Kualitas Bibit Terbaik Jika hasil dibawah itu berarti belum menghasilkan bibit terbaik. Penelitian ini menggunakan data 6 kriteria, dan 4 data alternatif. Didapatkan hasil keputusan dan akurasi Karet Jelutung (Dyera costulata) dengan nilai 0.5971 Menghasilkan Kualitas Bibit Terbaik, Karet Biasa dengan nilai 0.5014 Belum Menghasilkan Kualitas Bibit Terbaik, Karet Merah atau Karet Kebo (Ficus) dengan nilai 0.483 Belum Menghasilkan Kualitas Bibit Terbaik, Tanaman Russian Dandelion (Taraxacu) dengan nilai 0.4479 Belum Menghasilkan Kualitas Bibit Terbaik, Karet Brazil (Hevea Brasilliensis) dengan nilai 0.3921 Belum menghasilkan kualitas bibit terbaik, dan Tanaman Karet Guayule dengan nilai 0.2099 Belum menghasilkan kualitas bibit terbaik. 


\section{Implementasi Sistem} a.Menu Login

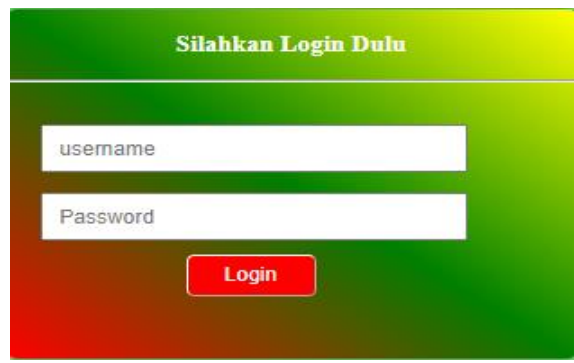

Gambar 6. Menu Login

Keterangan:

Menu Login digunakan untuk memulai masuk kedalam aplikasi. Jika username dan password benar maka akan masuk kedalam sistem. Jika tidak benar, maka akan mengulang sampai sesuai.

\section{b. Masuk Ke Aplikasi Utama}

Setelah tahapan form login dilakukan, maka selanjutnya adalah masuk ke menu utama untuk beberapa bagian menu program pada menu utama terdiri dari menu menu yang akan memproses perhitungan untuk mendapatkan hasil keputusan. Di sini, setiap menu program memiliki beberapa submenu pendukung yang menyediakan kemampuan untuk menampilkan formulir yang diperlukan. Tampilan menu untuk setiap program beserta tampilan menu program adalah sebagai berikut :

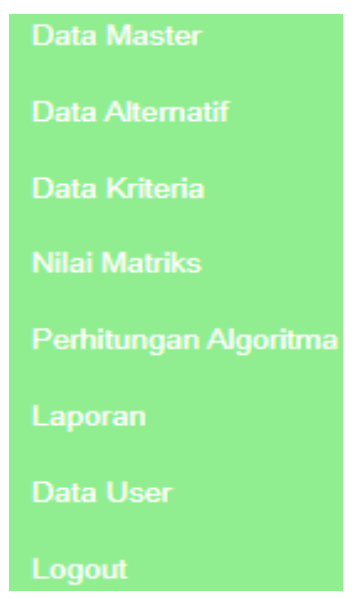

Gambar 7. Tampilan Menu Utama

\section{c. Menu Master}

Tampilan form ini berisikan tentang informasi data alternatif, data kriteria, dan user yang digunakan pada penelitian ini. Tampilan form dapat dilihat pada gambar berikut ini.

\begin{tabular}{|l|}
\hline \multicolumn{1}{|c|}{4} \\
Jumlah Data Kriteria \\
Bentuk Payung \\
Bentuk Daun \\
Helai Daun \\
Batang \\
\hline
\end{tabular}
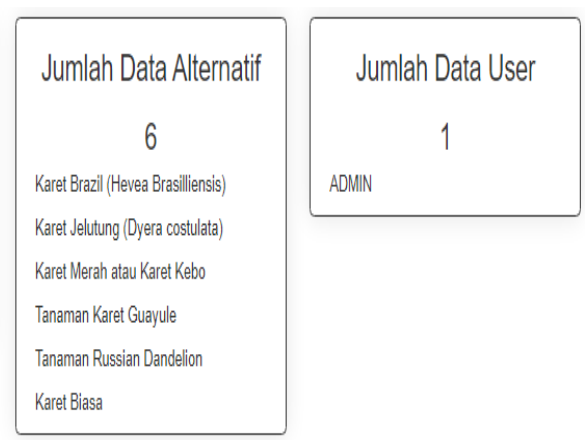

Gambar 8. Menu Master 


\section{d. Menu Data Alternatif}

Tampilan ini berisi informasi tentang data alternatif yang dipakai untuk penelitian. Didalam form data alternatif ini dapat dilakukan proses tambah, edit, hapus informasi tersebut. Tampilan form ini sebagai berikut ini:

\begin{tabular}{|c|c|c|c|}
\hline Data Alternatif & Tambah Alternatiff & & \\
\hline \multicolumn{4}{|c|}{ Data Alternatif } \\
\hline Id Alternatif & Nama Alternatif & Action & \\
\hline al0o1 & Karet Brazil (Hevea Brasililensis) & Ubah & Hapus \\
\hline al002 & Karet Jelutung (Dyera costulata) & Ubah & Hapus \\
\hline al003 & Karet Merah atau Karet Kebo & Ubah & Hapus \\
\hline al004 & Tanaman Karet Guayule & Ubah & Hapus \\
\hline al005 & Tanaman Russian Dandelion & Ubah & Hapus \\
\hline al0o6 & Karet Biasa & Ubah & Hapus \\
\hline
\end{tabular}

Gambar 9. Tampilan Form Data Alternatif

\section{e. Menu Data Kriteria}

Tampilan ini berisi informasi tentang data kriteria yang dipakai untuk penelitian. Didalam form data kriteria ini dapat dilakukan proses tambah, edit, hapus informasi tersebut.

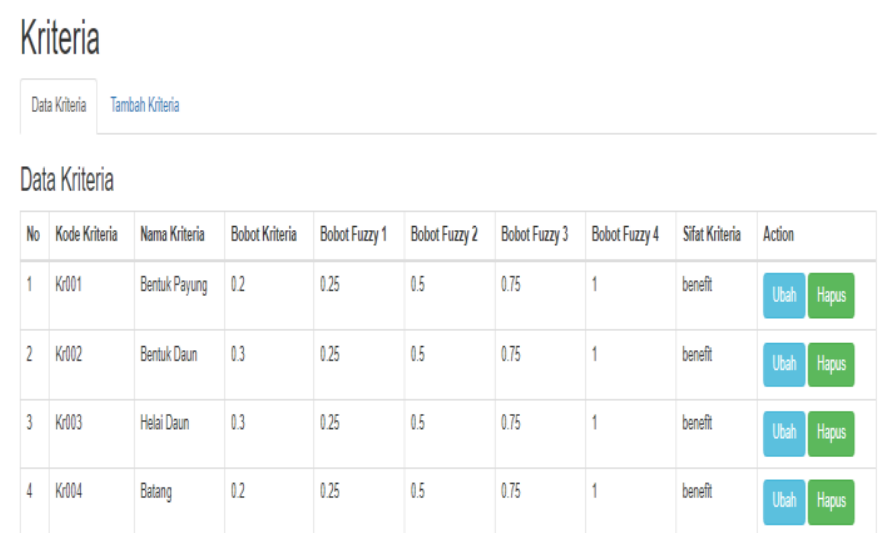

Gambar 10. Data Kriteria

\section{f. Hasil Keputusan}

Form Laporan ini berfungsi untuk melihat hasil perhitungan algoritma TOPSIS dari data alternatif, data kriteria, data matriks, dan bobot yang telah diberikan. Tampilan preview dapat dilihat dibawah ini:

Hasil Topsis

\begin{tabular}{|c|c|c|c|c|c|c|}
\hline Nllai Matuks & Nalai Matiks Temomalisasi & Nilai Bobat Temomalisasi & \multicolumn{2}{|c|}{ Matiks Ideal PosisisifiNegaliff } & Jarak Solusi liteal PosisitiliNegaziff & NilaiPreferensi \\
\hline \multicolumn{7}{|c|}{ Hapus Data Niliai Matitik } \\
\hline \multicolumn{7}{|c|}{ Nilai Preferensi } \\
\hline Nomor & & ama & $v_{i}$ & \multicolumn{3}{|c|}{ Keputusan } \\
\hline 1 & Karet Jelutung (Dyera costul & & 0.5971 & \multicolumn{3}{|c|}{ Menghasilkan Kualitas Bibit Terbaik } \\
\hline 2 & Karet Biasa & & 0.5014 & \multicolumn{3}{|c|}{ Belum Menghasilkan Kualitas Bibit Terbaik } \\
\hline 3 & Karet Merah atau Karet Kebc & & 0.483 & \multicolumn{3}{|c|}{ Belum Menghasilkan Kualitas Bibit Terbaik } \\
\hline 4 & Tanaman Russian Dandelion & & 0.4479 & \multicolumn{3}{|c|}{ Belum Menghasilkan Kualitas Bibit Terbaik } \\
\hline 5 & Karet Brazil (Hevea Brasillien & & 0.3921 & \multicolumn{3}{|c|}{ Belum Menghasilkan Kualitas Bibit Terbaik } \\
\hline 6 & Tanaman Karet Guayule & & 0.2099 & \multicolumn{3}{|c|}{ Belum Menghasilkan Kualitas Bibit Terbaik } \\
\hline
\end{tabular}

Gambar 11. Tampilan Hasil Keputusan Perhitungan Keputusan Metode TOPSIS 


\section{Kesimpulan}

Setelah melakukan berbagai macam tahapan-tahapan maka diperoleh suatu kesimpulan sebagai berikut:

1. Dengan menggunakan sistem Sistem Pendukung Keputusan Menentukan Kualitas jenis tanaman karet untuk menghasilkan bibit tanaman karet terbaik menggunakan metode TOPSIS, pengguna dapat menampilkan hasil bibit terbaik.

2. Hasil keputusan pada penelitian ini adalah Karet Jelutung (Dyera costulata) dengan tingkat akurasi sebesar 0.5971 menghasilkan kualitas bibit tanaman karet terbaik.

3. Dengan menggunakan sistem Sistem Pendukung Keputusan Menentukan Kualitas jenis tanaman karet untuk menghasilkan bibit tanaman karet terbaik menggunakan metode TOPSIS, pengguna dapat menampilkan hasil bibit terbaik dengan menggunakan PHP dan MySQL.

4. Sistem ini dapat membantu dan menjadi referensi bagi pihak balai penelitian tanaman karet dan karyawan dalam mendapatkan hasil bibit tanaman karet terbaik.

\section{Saran}

Adapun saran-saran yang dapat disampaikan dari hasil penelitian ini, antara lain:

1. Bagi pihak kampus dapat memberikan support lebih baik lagi agar kualitas hasil penelitian dapat meningkat kedepannya.

2. Bagi pihak penelitian tanaman karet, diharapkan agar pegawai yang mengoperasikan aplikasi ini diberikan pelatihan singkat agar tidak terjadi kesalahan dalam penginputan datanya.

3. Bagi mahasiswa diharapkan agar melanjutkan penelitian ini sehingga sistem pendukung keputusan ini dapat kembangkan lagi, terutama dalam segi fitur dan interface-nya. Supaya lebih menarik tampilannya dan lebih mudah dipakai.

4. Bagi mahasiswa agar penelitian ini disempurnakan kedepannya dengan menambah metode atau kombinasi metode agar mendapatkan tingkat akurasi yang cukup tinggi.

5. Bagi mahaiswa agar sistem ini dibuat secara online dan interface-nya dapat kembangkan lagi.

\section{Daftar Pustaka}

[1] Kidi \& Widyaiswara, “Teknologi Dan Aktivitas Dalam Kehidupan Manusia,” vol. 28, pp. 1-28, 2018.

[2] U. Memenuhi, S. Satu, and D. R. Pohan, "Jurusan Ilmu Komunikasi Fakultas Ilmu Sosial dan Ilmu Politik Universitas Muhammadiyah Malang," Skripsi Univ. Muhammadiyah Malang, pp. 45-54, 2018.

[3] P. Harianja, A. Saleh, and M. B. Akbar, "Sistem Pendukung Keputusan Penentuan Kualitas Tanaman Karet Menggunakan Metode Fuzzy Mamdani (Studi Kasus : PTPN III Medan),” Konf. Nas. Sist. Inf. 2018, pp. 1164-1174, 2018.

[4] F. Teknik and U. M. Kudus, “Analytical Hierarchy Process ),” pp. 115-119, 2017.

[5] S. Susmanto, Z. Zulfan, and M. Munawir, "Sistem Penerapan Fuzzy Multi Attribute Decision Making (MADM) Dalam Mendukung Keputusan Untuk Menentukan Lulusan Terbaik Pada Sekolah Tinggi Teknik Poliprofesi Medan,” J. Nas. Komputasi dan Teknol. Inf., vol. 1, no. 1, 2018.

[6] Sriani and R. A. Putri, “Analisa Sistem Pendukung Keputusan Mengunakan Metode TOPSIS Untuk Sistem Penerimaan Pegawai Pada SMA Al Washliyah Tanjung Morawa," J. Ilmu Komput. dan Inform., vol. 02, no. April, pp. 40-46, 2018.

[7] A. Hendini, "Pemodelan Uml Sistem Informasi Monitoring Penjualan Dan Stok Barang," J. Khatulistiwa Inform., vol. 2, no. 9, pp. 107-116, 2016.

[8] Fitri Ayu and Nia Permatasari, "perancangan sistem informasi pengolahan data PKL pada divisi humas PT pegadaian," J. Infra tech, vol. 2, no. 2, pp. 12-26, 2018. 